\title{
FAO-56 Penman-Monteith Daily ET from Linear Regression Calibrated Hargreaves Equation with Wind Terms in Tropics with Limited Data
}

\author{
Eric Kra \\ Agricultural Engineering Department, University of Ghana, P.O. Box LG77, Legon, Ghana \\ Correspondence should be addressed to Eric Kra; erickra@ug.edu.gh
}

Received 6 February 2014; Accepted 21 April 2014; Published 2 June 2014

Academic Editor: Silvia Imhoff

Copyright (c) 2014 Eric Kra. This is an open access article distributed under the Creative Commons Attribution License, which permits unrestricted use, distribution, and reproduction in any medium, provided the original work is properly cited.

\begin{abstract}
Hargreaves equation $(\mathrm{HG})$, which lacks a wind speed $\left(u_{2}\right)$ term, was modified, through a linear regression calibration method, into LHGu which has $u_{2}$ terms. LHGu is effectively a simplified method for approximating FAO-56 Penman-Monteith equation (FPM) daily reference evapotranspiration $\left(\mathrm{ET}_{o}\right)$ in tropics with only temperature data. In LHGu, the " 0.0023 " constant term in HG was calibrated as a shifted power function of $u_{2}$, and the calibration constant was parametrized as a quadratic function of $u_{2}$. LHGu was developed using simulated constant $u_{2}$ data and historical temperature data for four sites in West Africa: Abidjan, Accra, Daloa, and Lome. LHGu matched FPM ET ${ }_{o}$ better than HG over a wide range of $u_{2}$ : for Accra, for $u_{2}$ range $0.5-6.0 \mathrm{~m} / \mathrm{s}$, the modified coefficient of efficiency, $E_{1}$, varied narrowly (0.83-0.98) for LHGu but widely (0.14-0.95) for HG optimized for $u_{2}=2.0 \mathrm{~m} / \mathrm{s}$; the corresponding MBE ranges were $-0.05-0.01 \mathrm{~mm} / \mathrm{d}$ for LHGu and $0.02-0.63 \mathrm{~mm} / \mathrm{d}$ for HG which cannot respond to varying daily $u_{2}$. LHGu is useful for quickly computing practically accurate estimates of FPM ET $\mathrm{F}_{o}$ for varying daily $u_{2}$ where only temperature data are available.
\end{abstract}

\section{Introduction}

The Hargreaves equation (HG) [1] for estimating reference grass evapotranspiration $\left(\mathrm{ET}_{0}\right)$ is widely used around the globe for estimating evapotranspiration for various applications because it is mathematically very simple and requires only temperature data-a very big advantage in regions with limited weather data. However, it is not suitable for applications that involve estimating the effects of varying wind speed $\left(u_{2}\right)$ on $\mathrm{ET}_{o}$ estimates because it is normally calibrated for constant rather than variable $u_{2}$.

The most reliable alternative to using $\mathrm{HG}$ for quantifying the effects of varying $u_{2}$ on $\mathrm{ET}_{o}$ in limited data situations is the FAO-56 Penman-Monteith equation (FPM) which has terms for variable $u_{2}$. But FPM is complicated to use compared to HG since numerous intermediate computations need to be made to estimate the missing weather data; these computations create many potential error pitfalls for the nonexpert user and have thus inspired much research to simplify the estimation of $\mathrm{ET}_{o}$ by FPM [2-4].
The difficulties of applying FPM have also given rise to much research towards improving simpler empirical alternatives to FPM, especially HG, to match the accuracy of FPM (e.g., [5-8]). However, much of the literature on improving the simpler alternatives such as HG deals with fixed $u_{2}$ with little on variable $u_{2}$ conditions. This is a gap in the literature that needs to be filled with more research because wind speed greatly influences evapotranspiration $[9,10]$. What is particularly needed is a simple equation like the popular HG for variable wind speed conditions as an alternative to the computationally more challenging FPM when only temperature data are available.

The main challenge in developing simple variable wind $\mathrm{ET}_{o}$ equations is that wind speed in the field is unsteady over the day and thus it is impossible to obtain $\mathrm{ET}_{o}$ data for constant daily wind speeds under natural settings [11]. In the literature, when both wind and $\mathrm{ET}_{o}$ data are available, empirical equations are developed by simply analyzing $\mathrm{ET}_{o}$ data for average daily wind speeds rather than for constant speeds. The approach used in this study is different in not 
requiring actual wind data and it is therefore suitable for poor data situations where usually only temperature data are available; we circumvented the data problem using a methodology that is essentially the same as grafting the wind function of the widely accepted FPM into the Hargreaves equation. Thus, the resulting equation is really a computational shortcut for approximating FPM daily $\mathrm{ET}_{o}$ for variable $u_{2}$ conditions rather than another empirical alternative to FPM for data poor tropical sites.

The linear regression calibration method was chosen for this study because it is a popular method of calibrating empirical $\mathrm{ET}_{o}$ equations such as $\mathrm{HG}[9,12]$ even though there are more efficient methods for calibrating HG against FPM $[13,14]$. HG calibrated by the linear regression method is named LHG in this study. Because LHG lacks $u_{2}$ terms, its $\mathrm{ET}_{o}$ estimates are insensitive to even very large changes in $u_{2}$. The aim of this work was therefore to develop LHGu, a modification of LHG that includes terms for $u_{2}$, to be used as a simplified method of approximating FPM daily $\mathrm{ET}_{o}$ for varying $u_{2}$ where only temperature data are available. The objectives were to develop LHGu and evaluate its efficiency and accuracy for both constant daily $u_{2}$ and mixed-type daily $u_{2}$. The hypothesis of this work was that LHG which has no $u_{2}$ term can be modified into LHGu which has $u_{2}$ parameters from the envelopes of optimal calibration parameters of LHG at various $u_{2}$.

\section{Methodology}

This study focused on West Africa, using daily maximum and minimum temperature data from four weather stations: Accra $\left(5.55^{\circ} \mathrm{N}\right)$, Abidjan $\left(5.25^{\circ} \mathrm{N}\right)$, Daloa $\left(6.86^{\circ} \mathrm{N}\right)$, and Lome $\left(6.16^{\circ} \mathrm{N}\right)$. The calibration data used for Abidjan, Lome, and Daloa were 1999-2003 average daily data obtained from TuTiempo [15] and those for Accra were 1998-2006 average daily data from the Water Research Institute (WRI) in Accra. The test data for Abidjan, Lome, and Daloa were average 2004-2006 data and that for Accra were 2007 data.

The aim of the study was to place $u_{2}$ as a term in the linear regression calibrated HG equation, LHG; the modified LHG, LHGu, should produce $\mathrm{ET}_{o}$ estimates similar to those of FPM for $u_{2}$ in the range $0.5-6.0 \mathrm{~m} / \mathrm{s}$. Therefore, 56 different LHG (linear regression calibrated HG equations) were optimized against FPM at various possible values for $u_{2}$ in the range $0.5 \mathrm{~m} / \mathrm{s}-6.0 \mathrm{~m} / \mathrm{s}$ in steps of $0.1 \mathrm{~m} / \mathrm{s}$ for each of the four locations in West Africa. The optimizations were done to maximize the modified coefficient of efficiency, $E_{1}$, values while varying the $k_{\mathrm{HG}}$ and linear calibration constants $\left(k_{4}\right)$ values using the solver add-in in Microsoft Excel (version 2010). Simple mathematical functions were then developed to efficiently describe the envelopes of the generated optimum $k_{\mathrm{HG}}$ and $k_{4}$ versus $u_{2}$ data.

The resulting LHGu was tested with both fixed $u_{2}$ data and mixed uniformly distributed wind data generated using the Data Analysis Pack in Excel [16]; although wind data is normally described by the Weibull distribution [17] this study evaluated LHGu for the fixed and mixed data situations because the aim of the work was to develop $\mathrm{LHGu}$, to match FPM equally well at every $u_{2}$ in the $0.5-6.0 \mathrm{~m} / \mathrm{s}$ range regardless of wind distribution, rather than to be a new $\mathrm{ET}_{o}$ equation for estimating $\mathrm{ET}_{o}$ under one particular $u_{2}$ distribution only.

The FPM equation used was $[12,18]$

$$
\begin{aligned}
& \mathrm{ET}_{o, \mathrm{FPM}} \\
& =\frac{0.408 \Delta\left(R_{n}-G\right)+\gamma(900 /(T+273)) u_{2}\left(e_{s}-e_{a}\right)}{\Delta+\gamma\left(1+0.34 u_{2}\right)},
\end{aligned}
$$

where $\mathrm{ET}_{o, \mathrm{FPM}}$ is the reference grass evapotranspiration $\left(\mathrm{mm} \mathrm{d}^{-1}\right) ; R_{n}$ is the net radiation at the crop surface $\left(\mathrm{MJ} \mathrm{m}^{-2} \mathrm{~d}^{-1}\right) ; G$ is the soil heat flux density $\left(\mathrm{MJ} \mathrm{m}^{-2} \mathrm{~d}^{-1}\right) ; T$ is the mean daily air temperature at $2 \mathrm{~m}$ above ground $\left({ }^{\circ} \mathrm{C}\right)$; $u_{2}$ is the wind speed at $2 \mathrm{~m}$ above ground surface $\left(\mathrm{m} \mathrm{s}^{-1}\right) ; e_{s}$ is the saturation vapor pressure $(\mathrm{kPa}) ; e_{a}$ is the actual vapor pressure $(\mathrm{kPa}) ; \Delta$ is the slope of vapor pressure-temperature curve $\left(\mathrm{kPa}^{\circ} \mathrm{C}^{-1}\right) ; \gamma$ is the psychometric constant $\left(\mathrm{kPa}^{\circ} \mathrm{C}^{-1}\right)$ [12]. In this work, the required data to use (1) were missing except air temperature; thus missing data were estimated from temperature data using equations described in Allen et al. [12] and other sources (Kra [3]; ASCE-EWRI [18]).

The Hargreaves equation (HG) Hargreaves and Samani [19] used was

$$
\mathrm{ET}_{o, \mathrm{HG}}=0.0023 \times(T+17.8)\left(T_{x}-T_{n}\right)^{0.50} \frac{R_{a}}{\lambda},
$$

where $\mathrm{ET}_{o, \mathrm{HG}}$ is the reference grass evapotranspiration $\left(\mathrm{mm} \mathrm{d}^{-1}\right) ; T_{x}$ is the maximum daily temperature $\left({ }^{\circ} \mathrm{C}\right), T_{n}$ is the minimum daily temperature $\left({ }^{\circ} \mathrm{C}\right), T$ is the average temperature, $T=\left(T_{x}+T_{n}\right) / 2, R_{a}$ is the extraterrestrial radiation $\left(\mathrm{MJ} \mathrm{m}^{-2} \mathrm{~d}^{-1}\right)$, and $\lambda$ is the latent heat of vaporization (MJ kg ${ }^{-1}$ ), computed as $\lambda=2.501-0.002361 T$ in this study. For the purpose of this work, (2) was generalized as

$$
\mathrm{ET}_{o, \mathrm{LHG}}=k_{\mathrm{HG}} \times(T+17.8)\left(T_{x}-T_{n}\right)^{0.5} \frac{R_{a}}{\lambda}+k_{4},
$$

where the original parameter values are $k_{\mathrm{HG}}=0.0023$ and $k_{4}=0 \mathrm{~mm} \mathrm{~d}^{-1}$. Also, $k_{\mathrm{HG}}=k_{R S} \times k_{1}$; for locations near large water bodies, $k_{R S}=0.19$ [8], and thus $k_{1}=0.0121$. The calibration of $k_{\mathrm{HG}}$ and $k_{4}$ constants to make (3) match FPM with the highest efficiency for a whole year is referred to as linear regression calibration of Hargreaves (LHG) in this work.

2.1. Performance Parameters. The performance of the LHG and LHGu equations were measured using the following parameters applied to scatter plots of LHG and LHGu versus $\mathrm{FPM} \mathrm{ET}_{o}$ : the modified coefficient of efficiency $\left(E_{1}\right)$, mean absolute error (MAE), mean bias error (MBE), maximum absolute error (MxAE), coefficient of determination $\left(r^{2}\right)$, and slope of the linear regression line.

The modified coefficient of efficiency, $E_{1}$, $[20,21]$ was defined as

$$
E_{1}=1-\frac{\sum_{i=1}^{N}\left|\mathrm{ET}_{o, \mathrm{FPM}}^{i}-\mathrm{ET}_{o, \mathrm{LHGu}}^{i}\right|}{\sum_{i=1}^{N}\left|\mathrm{ET}_{o, \mathrm{FPM}}^{i}-\overline{\mathrm{ET}_{o, \mathrm{FPM}}}\right|},
$$


where $N$ is the total number of days of the year, $i$ is the the particular day of the year, and $\overline{\mathrm{ET}_{o, \mathrm{FPM}}}$ is the average $\mathrm{ET}_{o, \mathrm{FPM}}$ for the year.

The mean absolute error, MAE, was estimated using

$$
\mathrm{MAE}=\frac{1}{N} \sum_{i=1}^{N}\left|\mathrm{ET}_{o, \mathrm{FPM}}^{i}-\mathrm{ET}_{o, \mathrm{LHGu}}^{i}\right|
$$

where the variables are as defined in (4).

The annual mean bias error (MBE) was estimated as

$$
\mathrm{MBE}=\frac{1}{N} \sum_{i=1}^{N}\left(\mathrm{ET}_{o, \mathrm{LHGu}}^{i}-\mathrm{ET}_{o, \mathrm{FPM}}^{i}\right),
$$

which was defined to be positive when LHGu, on the average, overestimates $\mathrm{FPM} \mathrm{ET}_{o}$ and vice versa.

The annual maximum absolute error (MxAE) that was not considered an outlier was computed by

$$
\mathrm{MxAE}=\max \left(\left|\mathrm{ET}_{o, \mathrm{FPM}}^{i}-\mathrm{ET}_{o, \mathrm{LHGu}}^{i}\right|\right) .
$$

\section{Results}

In these results, LHGu is the modified Hargreaves equation that incorporates $u_{2}$ terms; LHG (without " $u$ ") is the Hargreaves equation which has been calibrated by the linear regression method for a specific $u_{2}$ value and therefore has no $u_{2}$ term.

3.1. Parametrization of $k_{H G}$ and $k_{4}$. The optimal $k_{\mathrm{HG}}$ versus $u_{2}$ data for LHG for the four sites were fitted, with $r^{2}>0.999$, by the general shifted power function:

$$
k_{\mathrm{HG}}=a \times\left(u_{2}+b\right)^{c}
$$

and the $k_{4}$ versus $u_{2}$ data were fitted, with $r^{2}>0.999$, by the general quadratic function:

$$
k_{4}=\alpha-\beta u_{2}+\gamma u_{2}^{2},
$$

where $a, b, c, \alpha, \beta$, and $\gamma$ were local fitting constants determined from temperature data for each site (Table 1). The $r^{2}>0.999$ applies only to the agreement between the $k_{\mathrm{HG}}$ and $k_{4}$ values and $u_{2}$ and not to LHG versus FPM. The lower graphs of Figure 1 show the $E_{1}$ and $r^{2}$ values, respectively, of the plots of LHG versus FPM at each of the $56 u_{2}$ values. It was not practical to plot all the 56 LHG and the 56 LHGu versus FPM plots for each site at calibration, but six examples from the application of LHG and LHGu to the Accra site are shown in Figure 2.

3.2. Accuracies of LHGu and LHG. Figure 3 shows the accuracies of previously calibrated LHGu and LHG measured by $E_{1}, r^{2}, \mathrm{MAE}, \mathrm{MBE}, \mathrm{MxAE}$, and slope of the scatter plots of LHGu versus FPM ET when applied to the 2007 Accra site daily temperature data and homogeneous daily $u_{2}$ data in the interest range. Each point in each graph represents the relevant performance parameter for each of the 56 scatter plots of LHGu versus FPM or one of the 56 scatter plots for

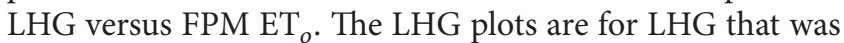
calibrated for $u_{2}=2.0 \mathrm{~m} / \mathrm{s}$ - the global average wind speed.

Table 2 highlights the numerical values of interest in Figure 3, showing the peak values of the performance measures and the wind speeds at which they occurred when LHGu and LHG were applied to the 2007 Accra data for the various homogeneous $u_{2}$ data.

3.3. Tractability of LHGu. Table 3 outlines the intermediate parameters required to apply LHGu, LHG, and FPM. $k_{\mathrm{HG}}$ and $k_{4}$ for LHGu were computed from (11) but were constants for LHG. The formulas for computing the intermediate parameters for FPM can be found in references such as Kra [3] or Allen et al. [12] and are therefore not reproduced here.

3.4. $L H G$ versus $L H G u$. The $E_{1}^{\max }$ of $L H G$ occurred at the $u_{2}$ for which it was calibrated against FPM, $u_{2}^{\text {calib }} . E_{1}$ reduced as $u_{2}$ increased or decreased from $u_{2}^{\text {calib }}$ at a much faster rate than for LHGu when moving away from $u_{2}^{\text {opt }}$. At any $u_{2}, E_{1}$ of LHG was always less than or equal to the $E_{1}$ of LHGu (Figure 3). Four other error parameters (MAE, MBE, MxAE, and slope) behaved like $E_{1}$, but, interestingly, $r^{2}$ did not indicate any difference between LHGu and LHG at any $u_{2}$ value (Figure 3). However, scatter plots showed that although $r^{2}$ of LHGu and LHG were equal at each $u_{2}$, the LHGu plots were significantly better aligned with the $1: 1$ line than the LHG plots (Figure 2).

Figure 2 shows snapshot comparisons of LHGu and LHG versus FPM when applied to three constant $u_{2}$ data for each day of 2007 Accra weather data; it compares the shapes of the scatter plots and the $E_{1}$ values for LHGu and LHG when $r^{2}$ values were constant at $u_{2}$ values of $0.5,2.0$, and $6.0 \mathrm{~m} / \mathrm{s}$.

Figure 4 compares the performance of LHGu and LHG applied to mixed $u_{2}$ data that were uniformly distributed across the range $0.5-6.0 \mathrm{~m} / \mathrm{s}$ and randomly distributed over all the days of the 2007 weather data for the Accra site.

\section{Discussion}

The results generally confirm that the wind terms of FPM can be grafted into the Hargreaves equation through the linear regression calibration method and that the new equation, LHGu, can be used as a fast, simple, and practically adequate method for approximating FPM daily $\mathrm{ET}_{o}$ estimates over a wide range of $u_{2}$ when only temperature data are available for tropical locations.

The discussions below show that LHGu is accurate enough to be used in place of FPM to reduce computational effort in $\mathrm{ET}_{o}$ applications involving varying annual homogeneous daily wind speed and those that use mixed $u_{2}$ data for different days of the year.

4.1. The LHGu Equation. The smooth and gradual variation of $k_{\mathrm{HG}}$ and $k_{4}$ with $u_{2}$ made it easy to parametrize them almost perfectly with $u_{2}$ as reflected in the extremely high values of $r^{2}>0.999$. Therefore, (8) and (9) are as good as the data from which they were derived (Figure 1). The 
TABLE 1: Local values for the $k_{\mathrm{HG}}$ and $k_{4}$ parameters of LHGu equation for $u_{2}$ range $0.5-6.0 \mathrm{~m} / \mathrm{s}$.

\begin{tabular}{|c|c|c|c|c|c|c|c|}
\hline \multirow{2}{*}{ Location } & \multirow{2}{*}{ Latitude $\left({ }^{\circ} \mathrm{N}\right)$} & \multicolumn{3}{|c|}{$k_{\mathrm{HG}}=a \times\left(u_{2}+b\right)^{c}$} & \multicolumn{3}{|c|}{$k_{4}=\alpha-\beta u_{2}+\gamma u_{2}^{2}$} \\
\hline & & $a$ & $b$ & $c$ & $\alpha$ & $\beta$ & $\gamma$ \\
\hline Abidjan & 5.25 & 0.00143 & 1.6508 & 0.4046 & 0.4875 & 0.3730 & 0.0174 \\
\hline Accra & 5.55 & 0.00135 & 1.7953 & 0.4406 & 0.4892 & 0.3924 & 0.0165 \\
\hline Daloa & 6.86 & 0.00137 & 1.7375 & 0.4348 & 0.7861 & 0.6029 & 0.0248 \\
\hline Lome & 6.16 & 0.00142 & 1.4993 & 0.4310 & 0.5616 & 0.4429 & 0.0204 \\
\hline
\end{tabular}

TABLE 2: Numerical highlights of Figure 3; $\Delta=$ Optimum - Nadir value of the test parameter.

\begin{tabular}{|c|c|c|c|c|c|c|c|c|c|c|}
\hline \multirow{2}{*}{$\begin{array}{l}\text { Test } \\
\text { parameter }\end{array}$} & \multicolumn{5}{|c|}{ LHGu } & \multicolumn{5}{|c|}{ LHG (calibrated at $u_{2}=2 \mathrm{~m} / \mathrm{s}$ ) } \\
\hline & Optimum & $u_{2}^{\mathrm{opt}}(\mathrm{m} / \mathrm{s})$ & Nadir & $u_{2}^{\text {nadir }}(\mathrm{m} / \mathrm{s})$ & $\Delta$ & Optimum & $u_{2}^{\mathrm{opt}}(\mathrm{m} / \mathrm{s})$ & Nadir & $u_{2}^{\text {nadir }}(\mathrm{m} / \mathrm{s})$ & $\Delta$ \\
\hline$E_{1}$ & 0.98 & 1.4 & 0.83 & 6.0 & 0.14 & 0.95 & 2.0 & 0.14 & 6.0 & 0.81 \\
\hline$r^{2}$ & 1.0 & 1.4 & 0.97 & 6.0 & 0.07 & 1.0 & 1.4 & 0.97 & 6.0 & 0.97 \\
\hline Slope & $0.9 \dot{9}$ & 1.8 & 0.93 & 6.0 & 0.07 & 0.99 & 2.0 & 0.68 & 6.0 & 0.68 \\
\hline $\operatorname{MAE}(\mathrm{mm} / \mathrm{d})$ & 0.01 & 1.4 & 0.12 & 6.0 & -0.11 & 0.02 & 2.0 & 0.63 & 6.0 & -0.60 \\
\hline $\operatorname{MBE}(\mathrm{mm} / \mathrm{d})$ & 0.01 & 1.3 & -0.03 & 6.0 & 0.04 & 0.01 & 1.9 & -0.63 & 6.0 & 0.64 \\
\hline $\operatorname{MxAE}(\mathrm{mm} / \mathrm{d})$ & 0.08 & 1.3 & 0.86 & 6.0 & -0.78 & 0.15 & 2.0 & 2.1 & 6.0 & -1.93 \\
\hline
\end{tabular}

successful parametrization of $k_{\mathrm{HG}}$ and $k_{4}$ implies that the complete LHGu equation was composed of (3), (8), and (9). For example, for Accra, the full LHGu equation was

$$
\mathrm{ET}_{o, \mathrm{LHGu}}=k_{\mathrm{HG}}\left(T_{x}-T_{n}\right)^{0.5}(T+17.8) \frac{R_{a}}{\lambda}+k_{4},
$$

where after substitution of the appropriate constants (Table 1)

$$
\begin{gathered}
k_{\mathrm{HG}}=0.00135 \times\left(u_{2}+1.7953\right)^{0.4406}, \\
k_{4}=0.4892-0.3924 u_{2}+0.0165 u_{2}^{2} .
\end{gathered}
$$

Although optimal $k_{\mathrm{HG}}$ increased while optimal $k_{4}$ decreased with $u_{2}$, their resultant effect caused LHGu ET $\mathrm{LT}_{o}$ to increase with $u_{2}$ over the range $0.5-6.0 \mathrm{~m} / \mathrm{s}$; they must therefore be applied together, not selectively, to avoid errors in estimating $\mathrm{ET}_{o}$.

4.2. Tractability of LHGu. LHGu is far less computationally intensive than FPM. The example of using LHGu to estimate $\mathrm{FPM} \mathrm{ET}_{o}$ for one day given in Table 3 shows that $\mathrm{LHGu}$ is only slightly more difficult to use than the original Hargreaves equation. The only difference between LHGu and LHG was the evaluations of the simple expressions of (11). Using FPM however required computing at least nine extra intermediate parameters many of which are more complicated than LHGu's.

LHGu is more foolproof than FPM. In the example of Table 3 there were fewer mistake pitfalls with LHGu than with FPM. Equation (11) had only simple algebraic expressions with only one variable, $u_{2}$, with familiar units $(\mathrm{m} / \mathrm{s})$ to note and is therefore not easy to slip with. Using FPM, however, required using many complicated and long equations with uncommon units and therefore presented many more opportunities for error; for example, some of the expressions required temperature in ${ }^{\circ} \mathrm{C}$ while others required it in $K$, thus presenting many more opportunities for mistakes than with LHGu.
TABLE 3: Example comparison of the number of intermediate calculations required to estimate $\mathrm{ET}_{o}$ for a day using $\mathrm{LHG}$, LHGu, and $\mathrm{FPM}$ for latitude $=5.55^{\circ} \mathrm{N}$, altitude $=69.0 \mathrm{~m}, T_{x}=32.6^{\circ} \mathrm{C}$, and $T_{n}=20.1^{\circ} \mathrm{C} ; u_{2}=3.2 \mathrm{~m} / \mathrm{s}$.

\begin{tabular}{lcccc}
\hline $\begin{array}{l}\text { Estimated } \\
\text { parameter }\end{array}$ & \multirow{2}{*}{ Units } & \multicolumn{3}{c}{$\mathrm{ET}_{o}$ equation } \\
& & LHG & LHGu & FPM \\
\hline$k_{\mathrm{HG}}$ & - & - & 0.0028 & - \\
$k_{4}$ & $\mathrm{Mm} \mathrm{d}^{-1}$ & - & -0.5979 & - \\
$R_{a}$ & $\mathrm{MJ} \mathrm{m}^{-2} \mathrm{~d}^{-1}$ & 22.7655 & 22.7655 & 22.7655 \\
$\Delta$ & $\mathrm{kPa}^{\circ} \mathrm{C}^{-1}$ & - & - & 0.2022 \\
$\gamma$ & $\mathrm{kPa}^{\circ}$ & - & - & 6.7096 \\
$e_{a}$ & $\mathrm{kPa}^{-1}$ & - & - & 2.3528 \\
$e_{s}$ & $\mathrm{kPa}$ & - & - & 3.6356 \\
$R_{s}$ & $\mathrm{MJ} \mathrm{m}^{-2} \mathrm{~d}^{-1}$ & - & - & 33.8897 \\
$R_{s o}$ & $\mathrm{MJ} \mathrm{m}^{-2} \mathrm{~d}^{-1}$ & - & - & 25.4641 \\
$R_{\mathrm{nl}}$ & $\mathrm{MJ} \mathrm{m}^{-2} \mathrm{~d}^{-1}$ & - & - & 4.2461 \\
$R_{\mathrm{ns}}$ & $\mathrm{MJ} \mathrm{m}^{-2} \mathrm{~d}^{-1}$ & - & - & 17.5294 \\
$R_{n}$ & $\mathrm{MJ} \mathrm{m}^{-2} \mathrm{~d}^{-1}$ & - & - & 13.2834 \\
$\mathrm{ET}_{o}$ & $\mathrm{~mm} \mathrm{~d}^{-1}$ & 5.0 & 5.4 & 5.6 \\
\hline & & & &
\end{tabular}

4.3. Comparisons. The different values of the parameters of (8) and (9) for the four sites meant that they intersected one another and with the $k_{\mathrm{HG}}=0.0023$ and the $k_{4}=0$ lines at different $u_{2}$ values. Although the closeness of the points of intersection suggests that functions with certain common parameter values could be derived for the four sites, this was not attempted since the main aim of this study was rather to prove that LHGu was possible.

The main difference between LHGu and other simplifications of FPM in the literature such as Valiantzas [22] is that (10) has the form of a familiar popular simple equation-the Hargreaves equation. It is also different from the alternative approaches of fitting a $u_{2}$ function to the FPM/HG ratio 


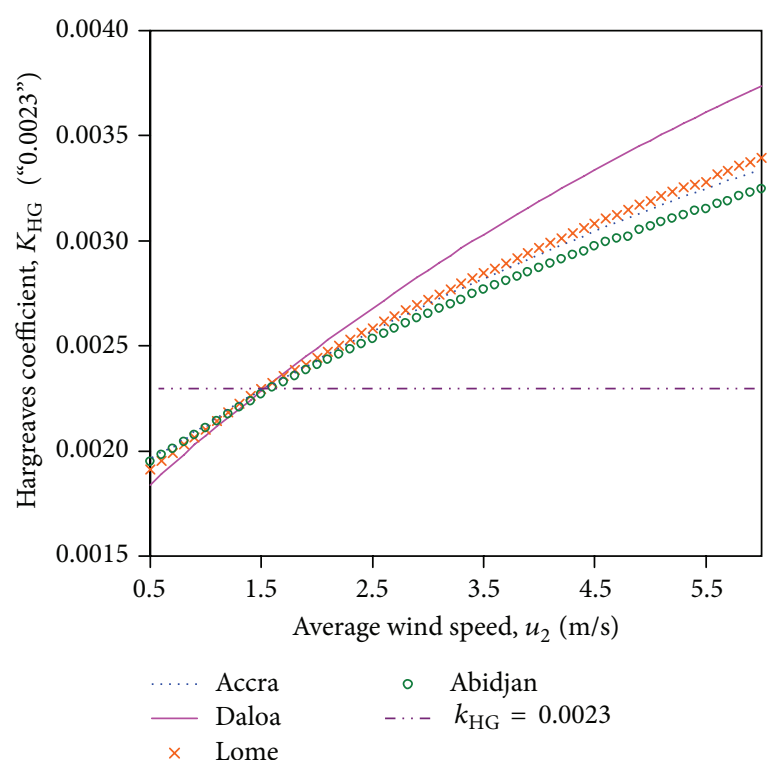

(a)

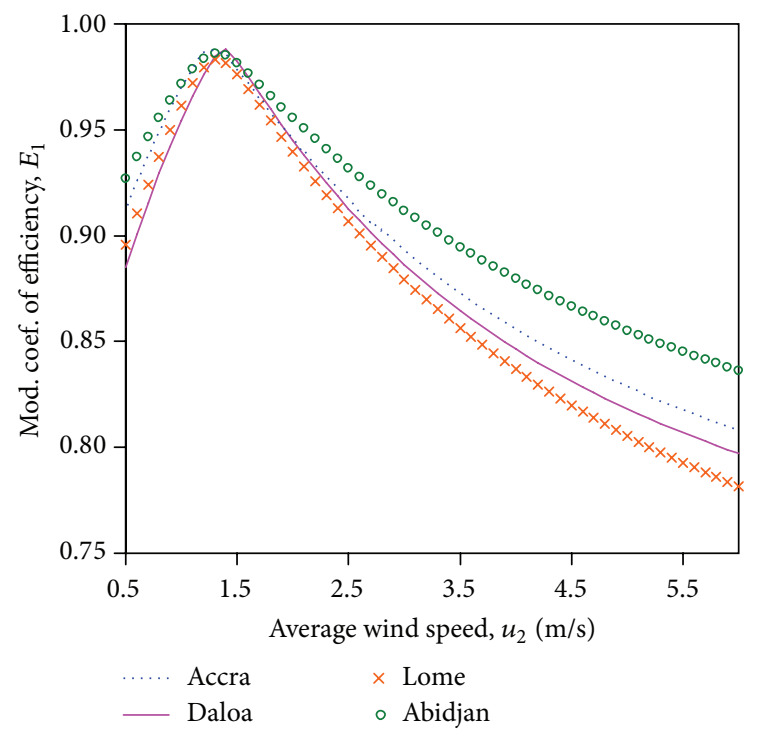

(c)

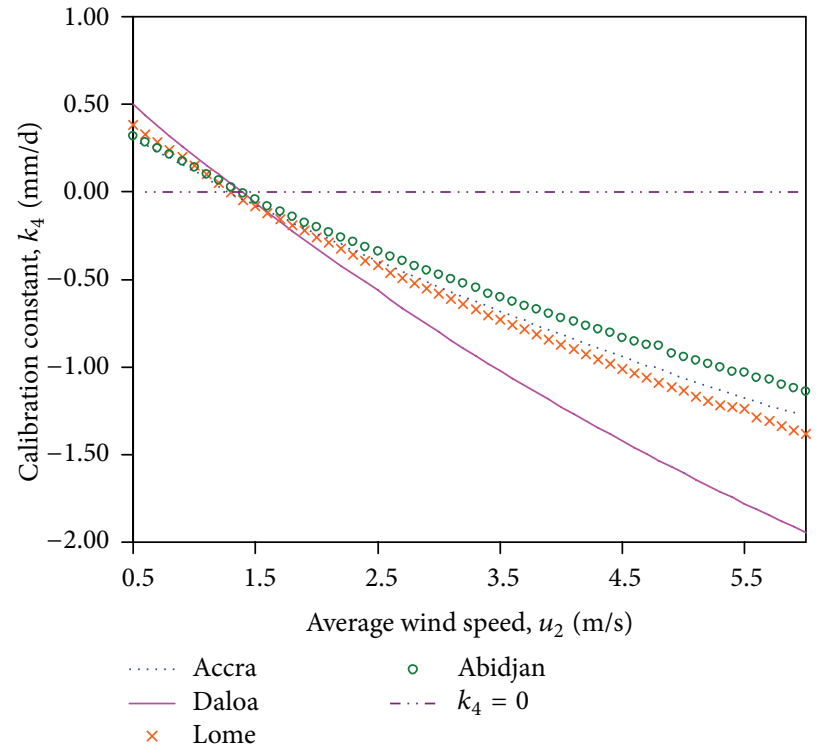

(b)

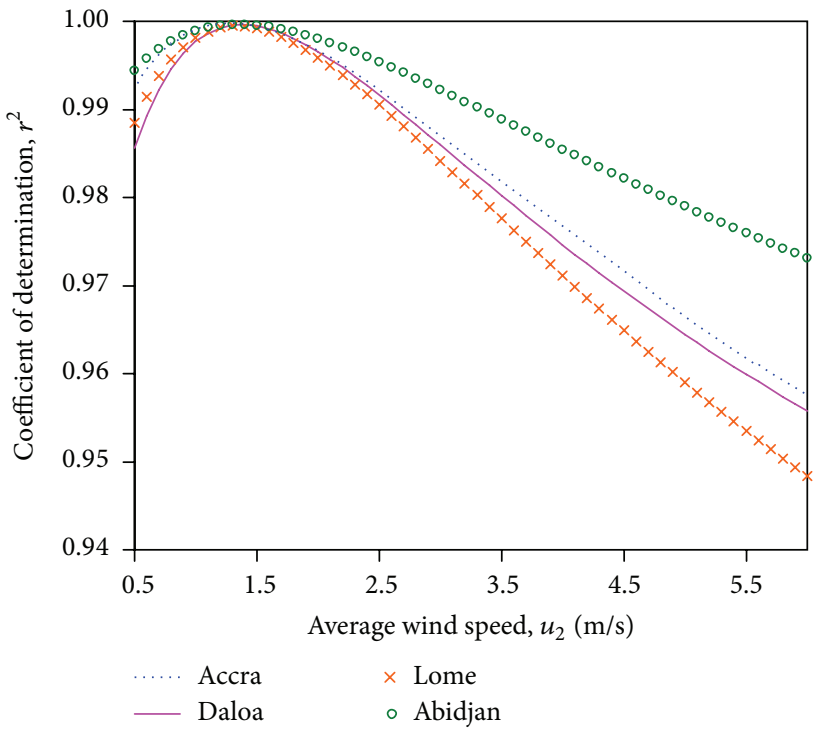

(d)

Figure 1: Calibrated optimal values of $k_{\mathrm{HG}}$ and $k_{4}$ for LHG and corresponding $E_{1}$ and $r^{2}$ for $u_{2}$ in the range $0.5-6.0 \mathrm{~m} / \mathrm{s}$ for Abidjan, Accra, Daloa, and Lome.

used by some researchers in that (8) and (9) together appear more complicated than the simple power functions used by Martinez-Cob and Tejero-Juste [23]. However, LHGu achieved extremely much higher $r^{2}$ values in the range 0.980.99 (Table 4) under similar tests than those reported by Martinez-Cob and Tejero-Juste [23] and Jensen et al. [10]. The much higher $r^{2}$ values may be attributed to the presence of the $u_{2}$ parametrized $k_{4}$ which is absent in the other studies, but further studies directly comparing the two methods will need to confirm this.

Another significant difference between LHGu and similar works in the literature is the method of development of the wind functions. While the wind functions for the FPM/HG ratio equations in the literature were developed for the entire considered wind speed range at once by minimizing the total error for the range, the wind functions for LHGu were developed independently for each of the 56 discrete wind speeds in the $0.5-6.0 \mathrm{~m} / \mathrm{s}$ range before combining them into (8) and (9). Therefore the lower efficiencies of the wind function at higher wind speeds did not affect the higher efficiencies which centered around $u_{2}^{\text {opt }}$ (Figure 1). Figure 3 shows the test statistics when LHGu and LHG were tested with homogeneous $u_{2}$ data and therefore indicates the maximum potential of LHGu and LHG as replacements for FPM at each $u_{2}$. Thus, LHGu applied to mixed $u_{2}$ data situations found in nature will perform below $E_{1}^{\mathrm{opt}}$ of LHGu. 

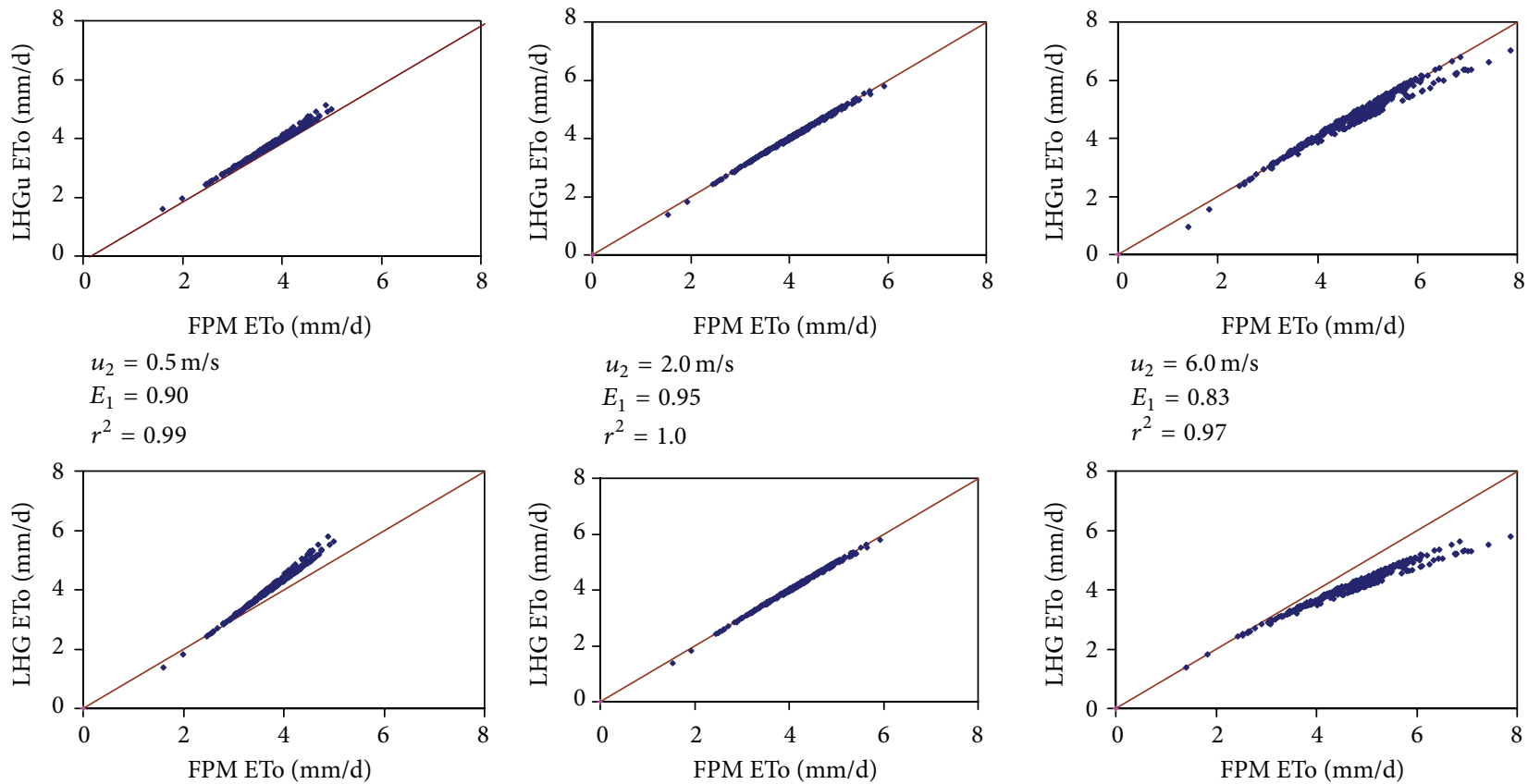

$$
\begin{aligned}
u_{2} & =2.0 \mathrm{~m} / \mathrm{s} \\
E_{1} & =0.95 \\
r^{2} & =1.0
\end{aligned}
$$

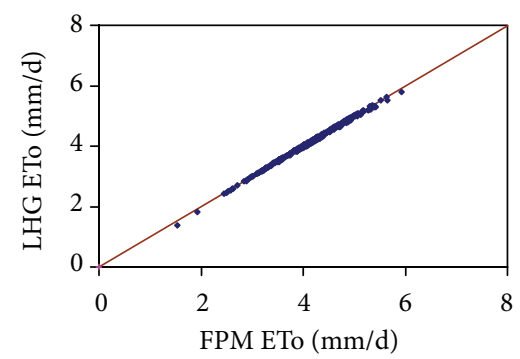

$$
\begin{aligned}
u_{2} & =6.0 \mathrm{~m} / \mathrm{s} \\
E_{1} & =0.83 \\
r^{2} & =0.97
\end{aligned}
$$

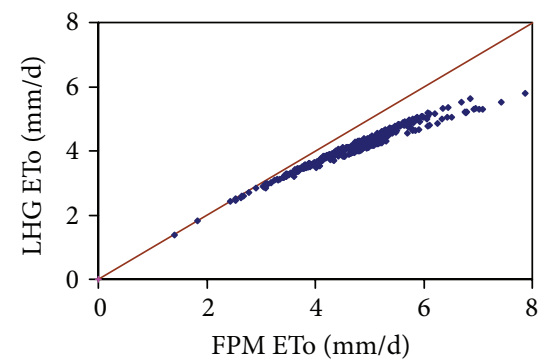

$$
\begin{aligned}
& u_{2}=0.5 \mathrm{~m} / \mathrm{s} \\
& E_{1}=0.20 \\
& r^{2}=0.99
\end{aligned}
$$

$$
\begin{aligned}
u_{2} & =2.0 \mathrm{~m} / \mathrm{s} \\
E_{1} & =0.95 \\
r^{2} & =1.0
\end{aligned}
$$

$$
\begin{aligned}
& u_{2}=6.0 \mathrm{~m} / \mathrm{s} \\
& E_{1}=0.14 \\
& r^{2}=0.97
\end{aligned}
$$

FIGURE 2: Scatter plots of LHGu and LHG versus FPM applied to 2007 Accra site data at three sample constant daily $u_{2}$ values, showing $r^{2}$, $E_{1}$, and scatter plot alignments with the $1: 1$ lines.
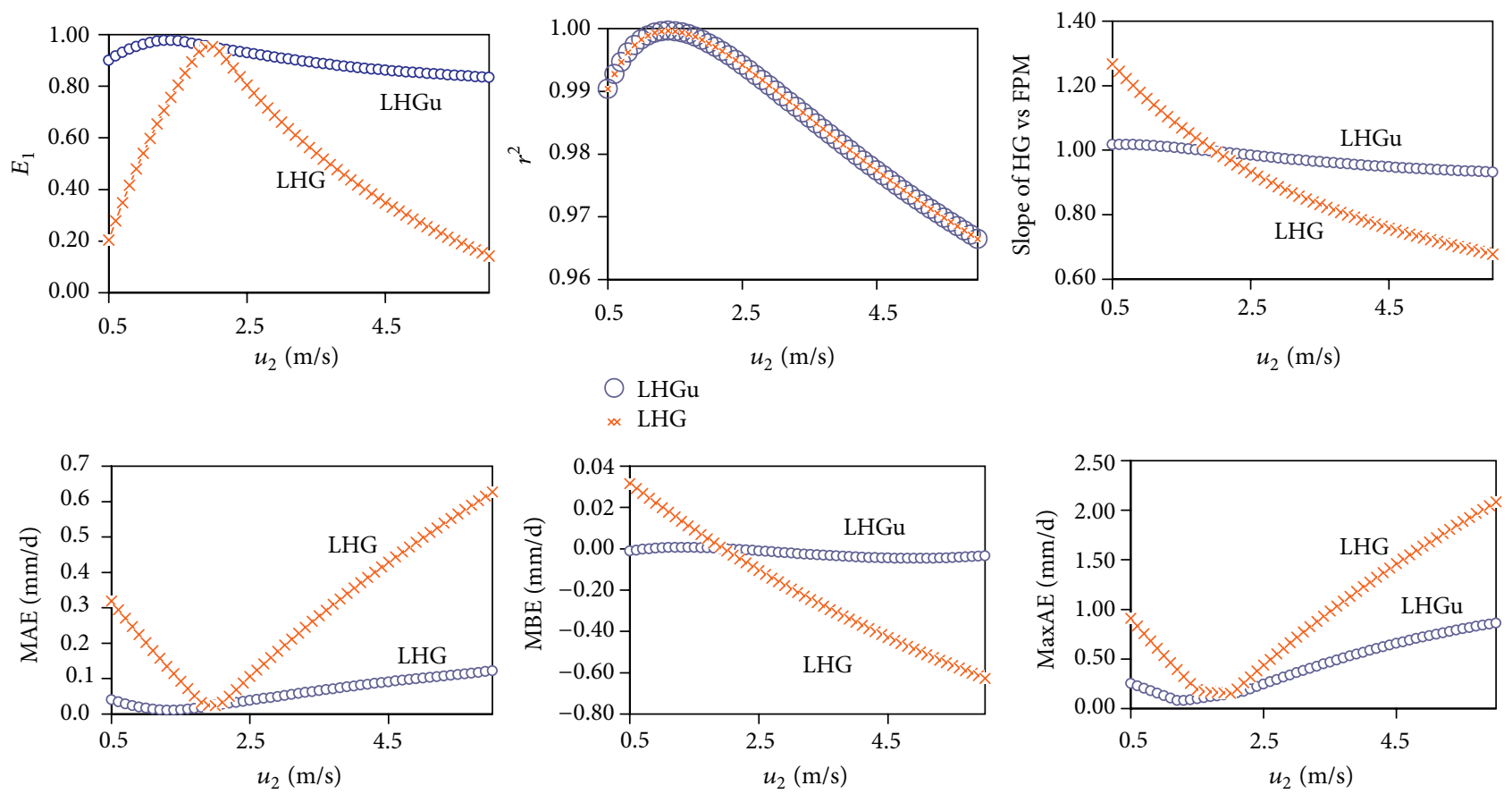

FIGURE 3: Performance statistics ( $E_{1}$, slope, MxAE, MBE, MAE, and $\left.r^{2}\right)$ of LGHu and LHG when applied to various constant daily $u_{2}$ data and 2007 Accra temperature data to estimate FPM ET, . 

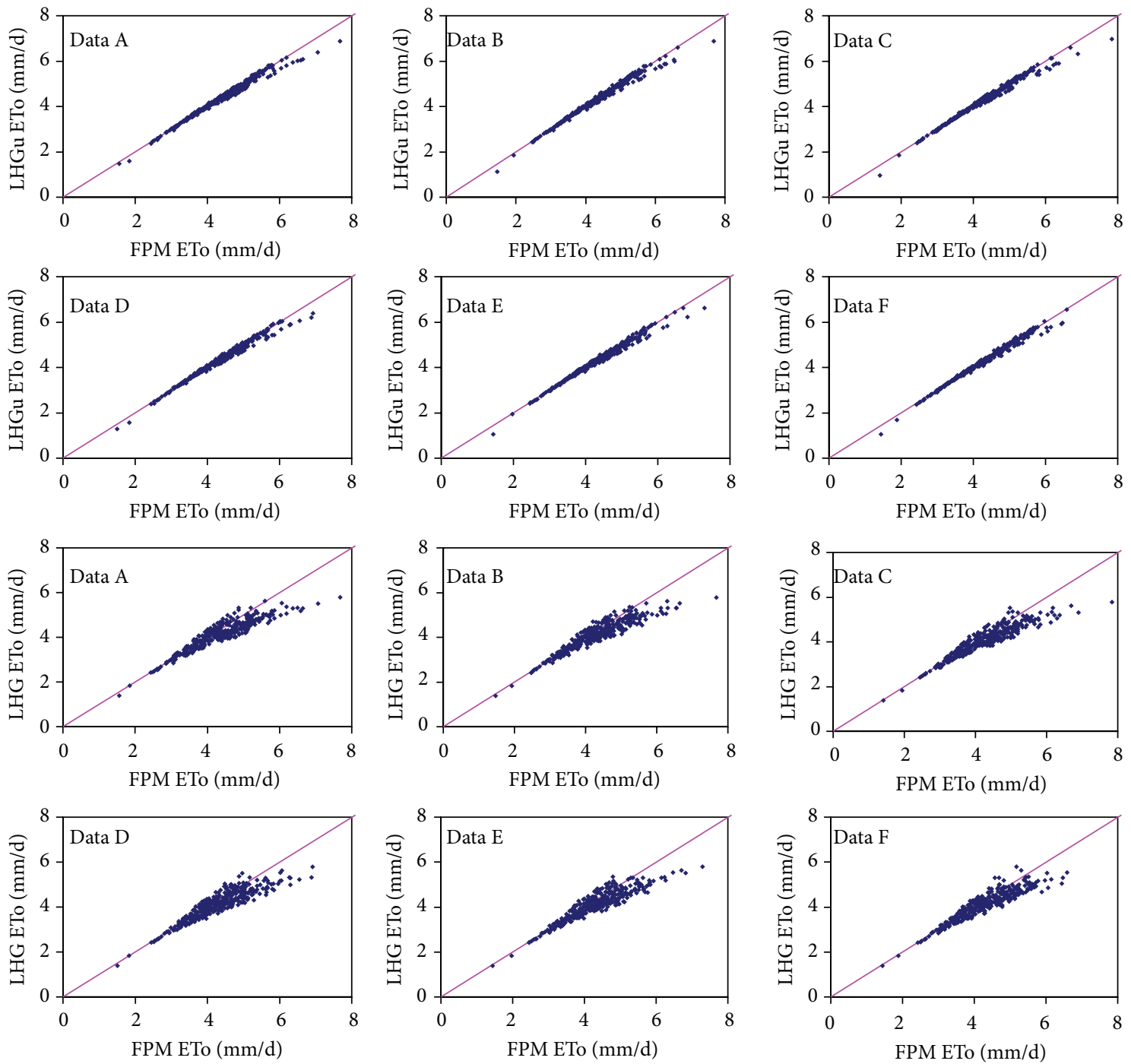

FIGURE 4: LHGu matched FPM far more precisely than LHG when applied to six different simulated mixed uniform daily $u_{2}$ data ranging $0.5-6.0 \mathrm{~m} / \mathrm{s}$ and 2007 Accra site temperature data.

TABLE 4: Performance parameters of LHGu and LHG against FPM when applied to six different simulated mixed $u_{2}$ data in the range 0.5$6.0 \mathrm{~m} / \mathrm{s}$ and 2007 weather data for the Accra site.

\begin{tabular}{lccccccccccccc}
\hline \multirow{2}{*}{ Parameter } & \multicolumn{2}{c}{ Data A } & \multicolumn{2}{c}{ Data B } & \multicolumn{2}{c}{ Data C } & \multicolumn{2}{c}{ Data D } & \multicolumn{2}{c}{ Data E } & \multicolumn{2}{c}{ Data F } \\
& LHG & LHGu & LHG & LHGu & LHG & LHGu & LHG & LHGu & LHG & LHGu & LHG & LHGu \\
\hline$E_{1}$ & 0.52 & 0.90 & 0.55 & 0.90 & 0.54 & 0.90 & 0.53 & 0.90 & 0.53 & 0.90 & 0.56 & 0.91 \\
$r^{2}$ & 0.85 & 0.98 & 0.86 & 0.98 & 0.86 & 0.98 & 0.83 & 0.98 & 0.84 & 0.98 & 0.85 & 0.99 \\
Slope & 0.71 & 0.95 & 0.74 & 0.95 & 0.73 & 0.96 & 0.74 & 0.95 & 0.75 & 0.96 & 0.76 & 0.98 \\
MAE $(\mathrm{mm} / \mathrm{d})$ & 0.32 & 0.07 & 0.28 & 0.06 & 0.30 & 0.06 & 0.29 & 0.06 & 0.28 & 0.06 & 0.27 & 0.05 \\
MBE $(\mathrm{mm} / \mathrm{d})$ & -0.23 & -0.03 & -0.20 & -0.02 & -0.22 & -0.02 & -0.19 & -0.02 & -0.19 & -0.02 & -0.18 & -0.02 \\
MaxAE $(\mathrm{mm} / \mathrm{d})$ & 1.89 & 0.80 & 1.89 & 0.80 & 2.05 & 0.85 & 1.57 & 0.67 & 1.51 & 0.67 & 1.39 & 0.52 \\
\hline
\end{tabular}

Table 4 shows the performance of LHGu when applied to uniformly mixed $u_{2}$ data in the range $0.5-6.0 \mathrm{~m} / \mathrm{s}$.

For actual wind speed distributions the performance of LHGu with real data can be worse or better than the uniform distribution performance shown in Table 4 and Figure 4. If the wind speed distribution is skewed toward $u_{2}^{\text {opt }}$ the performance will be better and vice versa, but the performance cannot exceed $E_{1}^{\text {opt }}$ neither can it fall below $E_{1}^{\text {min }}$, the best performance for homogeneous wind speed distribution at the maximum wind speed in the actual wind data. Thus although LHGu was not applied to actual wind data in this study we may conclude from the calibration 
of LHGu for Accra and the results of its application to homogeneous $u_{2}$ distribution data that for real $u_{2}$ data for Accra, $E_{1}$ will be within $0.81-0.99$ while $r^{2}$ will be within $0.96-1.00$ for the $0.5-6.0 \mathrm{~m} / \mathrm{s} \quad u_{2}$ range. Nevertheless, the objective of this work was not to make LHGu match FPM for only actual wind distribution data but any type of wind distribution in the range of interest so that it can be used to circumvent the more demanding intermediate computations of FPM when the available weather data is limited.

Although the above discussions used $E_{1}$ and $r^{2}$ they can be equally extended to the other test parameters: MAE, MBE, MxAE, and slope of the scatter plots of LHG and LHGu versus FPM. All the test parameters were consistent with $E_{1}$ at all $u_{2}$. All the test parameters were consistent in showing that LHGu was more accurate than LHG for both the homogeneous and the mixed uniform $u_{2}$ data, except $r^{2}$ which was interestingly the equal for both at every $u_{2}$ for both calibration and testing with the homogeneous $u_{2}$ data suggesting, contrary to the others, that there was absolutely no difference between LHGu and LHG (Figure 3). The three samples of the 56 pairs of LHGu and LHG versus FPM in Figure 2 show that even though the $r^{2}$ were the same, the LHGu plots were much better aligned with the 1:1 lines, hence visually confirming the indications of the other test parameters that LHGu was much more accurate than LHG.

There was another curious finding about the behavior of $r^{2}$ when LHG was applied with homogeneous $u_{2}$ data to the 2007 Accra site temperature data. The $r^{2}$ versus $u_{2}$ for LHG was always the same (as in Figure 3 ) regardless of the $u_{2}$ of calibration, but the calibration $u_{2}$ influenced the shapes of the curves of all the other test parameters when LHG was subsequently applied to FPM data. For example, LHG calibrated at $u_{2}=2.0 \mathrm{~m} / \mathrm{s}$ attained a higher $r^{2}$ at $u_{2}=1.4 \mathrm{~m} / \mathrm{s}$ than at $2.0 \mathrm{~m} / \mathrm{s}$. Although the unexpected behavior of $r^{2}$ is explained by the fact that $r^{2}$ is a measure of correlation rather than of model performance (Legates and McCabe [21]), its behavior implies that using $r^{2}$ alone without other test parameters can lead to the erroneous conclusion that there was no significant gain in putting wind terms into the Hargreaves equation. Therefore $r^{2}$ must not be used alone to compare models although the practice is common in the literature. There was no $r^{2}$ puzzle for the mixed $u_{2}$ data plots where the indications of $r^{2}$ agreed with the others (Figure 4 and Table 4).

4.4. Point Comparisons of LHGu and FPM. The expected errors when using LHGu to approximate $\mathrm{FPM} \mathrm{ET}_{o}$ for single computations depend on the $u_{2}$ data. The expected error increased with distance from $u_{2}^{\text {opt }}$. Thus when $u_{2}$ was about $1.3 \mathrm{~m} / \mathrm{s} \mathrm{LHGu}$ estimated FPM daily $\mathrm{ET}_{o}$ with efficiency of $E_{1}$ as high as 0.99 for Accra, which translated to MBE and MAE of merely $0.01 \mathrm{~mm} / \mathrm{d}$ and maximum absolute error, MxAE of merely $0.08 \mathrm{~mm} / \mathrm{d}$ (Figure 3 ). That implies that regardless of the temperature data, LHGu can estimate FPM ET virtually perfectly when $u_{2}$ is about $1.3 \mathrm{~m} / \mathrm{s}$. LHG can also estimate $\mathrm{FPM} \mathrm{ET}_{o}$ to the same accuracy but only if it had previously been optimized for that particular $u_{2}$. At the generally used global average wind speed of $2.0 \mathrm{~m} / \mathrm{s}$ there was only a slight decrease in the fidelity of LHGu to FPM. Even at $6.0 \mathrm{~m} / \mathrm{s}$ the MAE and MBE were only $0.12 \mathrm{~mm} / \mathrm{d}$ and $-0.13 \mathrm{~mm} / \mathrm{d}$, respectively, significantly less than those for LHG. But MxAE of $0.9 \mathrm{~mm} / \mathrm{d}$ may not be acceptable for some applications where accurate daily estimates are important. Therefore, LHGu is suitable for individual calculations around $u_{2}=1.3 \mathrm{~m} / \mathrm{s}$, but for farther $u_{2}$ the original FPM is more appropriate for some applications. Other methods of calibrating Hargreaves may be explored for accuracies better than possible with LHGu.

4.5. Limitations of LHGu. Although LHGu matched FPM virtually perfectly at many wind speeds and for many days, the scatter plots and the nonperfect test scores of $E_{1}$ and $r^{2}$ also showed that LHGu is not a perfect approximator of FPM, especially at higher wind speeds and $\mathrm{ET}_{0}$. This work was only part of a bigger research to simplify and reduce the number of intermediate steps required to apply FPM in limited data conditions in the tropics. Continuing research will explore other methods of calibrating HG and other simple $\mathrm{ET}_{o}$ equations to develop better procedures than LHGu.

\section{Conclusions}

Hargreaves equation can be modified to include wind speed terms without the use of actual wind data. The modified linear regression calibrated Hargreaves equation, LHGu, is significantly simpler to use and requires significantly fewer computations than FPM. LHGu approximates FPM well for the practical purposes of finding the effect of changing wind speeds on daily FPM ET ${ }_{o}$ estimates both for changing constant daily wind speeds and for a mixture of different daily wind speeds for a whole year, when only temperature data are available. Developing LHGu requires only daily historical temperature data and the range of possible daily wind speeds. Across the $u_{2}$ range $0.5-6.0 \mathrm{~m} / \mathrm{s}$, LHGu is significantly more accurate than the simple Hargreaves equation which lacks wind speed terms. The method used to develop LHGu is effectively a procedure for grafting FPM's aerodynamic terms into the calibration of Hargreaves. LHGu is not a perfect replacement for FPM, but more accurate approximations than LHGu may be developed by applying the methodology of this work to other methods of calibrating Hargreaves and to other simple $\mathrm{ET}_{o}$ equations.

\section{Conflict of Interests}

The author declares that there is no conflict of interests regarding the publication of this paper.

\section{References}

[1] G. H. Hargreaves and Z. A. Samani, "Reference crop evapotranspiration from ambient air temperature," in Proceedings of the Winter Meeting of the American Society of Agricultural Engineers, Paper no. 85-2517, Chicago, Ill, USA, December 1985.

[2] J. D. Valiantzas, "Simplified versions for the Penman evaporation equation using routine weather data," Journal of Hydrology, vol. 331, no. 3-4, pp. 690-702, 2006. 
[3] E. Y. Kra, "An empirical simplification of the temperature Penman-Monteith model for the tropics," The Journal of Agricultural Science, vol. 2, no. 1, pp. 162-171, 2010.

[4] M. N. ElNesr and A. A. Alazba, "Simple statistical equivalents of Penman-Monteith formula's parameters in the absence of nonbasic climatic factors," Arabian Journal of Geosciences, vol. 5, no. 4, pp. 757-767, 2012.

[5] P. Droogers and R. G. Allen, "Estimating reference evapotranspiration under inaccurate data conditions," Irrigation and Drainage Systems, vol. 16, no. 1, pp. 33-45, 2002.

[6] H. R. Fooladmand, H. Zandilak, and M. H. Ravanan, "Comparison of different types of Hargreaves equation for estimating monthly evapotranspiration in the South of Iran," Archives of Agronomy and Soil Science, vol. 54, no. 3, pp. 321-330, 2008.

[7] S. Subburayan, A. Murugappan, and S. Mohan, "Modified Hargreaves equation for estimation of ETo in a hot and humid location in Tamilnadu State, India," International Journal of Engineering Science and Technology, vol. 3, no. 1, pp. 592-600, 2011.

[8] G. H. Hargreaves and R. G. Allen, "History and evaluation of Hargreaves evapotranspiration equation," Journal of Irrigation and Drainage Engineering, vol. 129, no. 1, pp. 53-63, 2003.

[9] S. Shahidian, R. P. Serralheiro, J. Serrano, and J. L. Teixeira, "Parametric calibration of the Hargreaves-Samani equation for use at new locations," Hydrological Processes, vol. 27, pp. 605616, 2013.

[10] D. T. Jensen, G. H. Hargreaves, B. Temesgen, and R. G. Allen, "Computation of ETo under nonideal conditions," Journal of Irrigation and Drainage Engineering, vol. 123, no. 5, pp. 394-400, 1997.

[11] C.-R. Chu, M.-H. Li, Y.-Y. Chen, and Y.-H. Kuo, "A wind tunnel experiment on the evaporation rate of class A evaporation pan," Journal of Hydrology, vol. 381, no. 3, pp. 221-224, 2010.

[12] R. G. Allen, L. S. Pereira, D. Raes, and M. Smith, Crop Evapotranspiration-Guidelines for Computing Crop Water Requirements, FAO Irrigation and Drainage. Paper no. 56, Food and Agricultural Organization of the United Nations, Rome, Italy, 1998.

[13] E. Y. Kra, "Hargreaves equation as an all-season simulator of daily FAO-56 Penman-Monteith ETo," Agricultural Science, vol. 1, no. 2, pp. 43-52, 2013.

[14] S. Trajkovic, "Hargreaves versus Penman-Monteith under humid conditions," Journal of Irrigation and Drainage Engineering, vol. 133, no. 1, pp. 38-42, 2007.

[15] TuTiempo, "Tutiempo weather data website," 2009, http://www .tutiempo.net.

[16] K. N. Berk and P. Carey, Data Analysis with Microsoft Excel: Updated for Office 2007, Cengage Brain, 2009.

[17] M. Fidan, F. O. Hocaoğlu, and Ö. N. Gerek, "Improved synthetic wind speed generation using modified mycielski approach," International Journal of Energy Research, vol. 36, no. 13, pp. 1226-1237, 2012.

[18] ASCE-EWRI, The ASCE Standardized Reference Evapotranspiration Equation: Standardization of Reference Evapotranspiration Task Committee Report, ASCE-EWRI, Reston, Va, USA, 2005.

[19] G. H. Hargreaves and Z. A. Samani, "Reference crop evapotranspiration from temperature," Applied Engineering in Agriculture, vol. 1, no. 2, pp. 96-99, 1985.

[20] W. E. Bardsley and J. M. Purdie, "An invalidation test for predictive models," Journal of Hydrology, vol. 338, no. 1-2, pp. 57-62, 2007.
[21] D. R. Legates and G. J. McCabe Jr., "Evaluating the use of "goodness-of-fit" measures in hydrologic and hydroclimatic model validation," Water Resources Research, vol. 35, no. 1, pp. 233-241, 1999.

[22] J. D. Valiantzas, "Simple ETo forms of Penman's equation without wind and/or humidity data II comparisons with reducedset FAO and other methodologie," Journal of Irrigation and Drainage Engineering, vol. 139, pp. 9-19, 2013.

[23] A. Martinez-Cob and M. Tejero-Juste, "A wind-based qualitative calibration of the Hargreaves ETo estimation equation in semiarid regions," Agricultural Water Management, vol. 64, no. 3, pp. 251-264, 2004. 


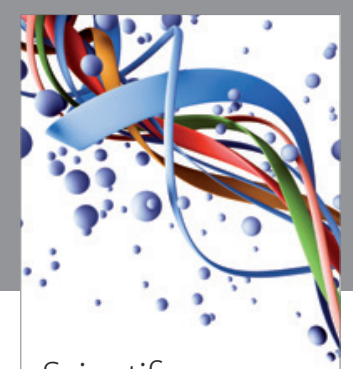

Scientifica
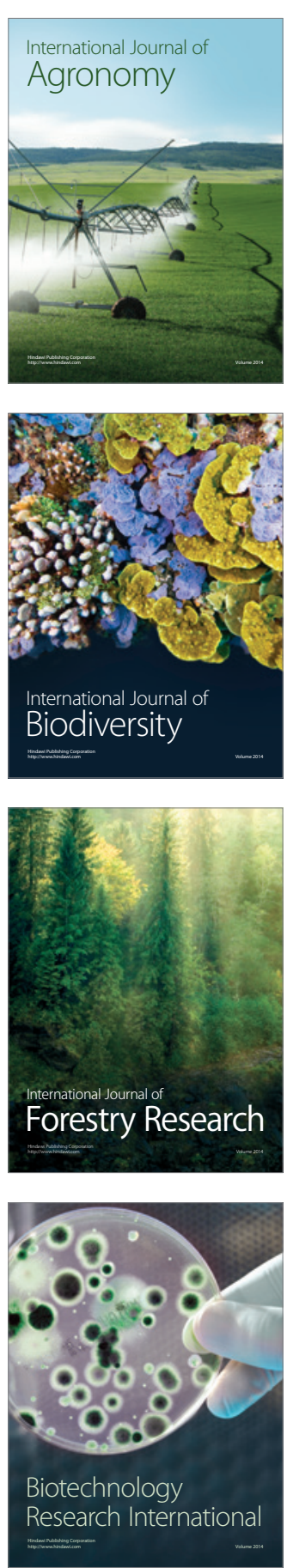
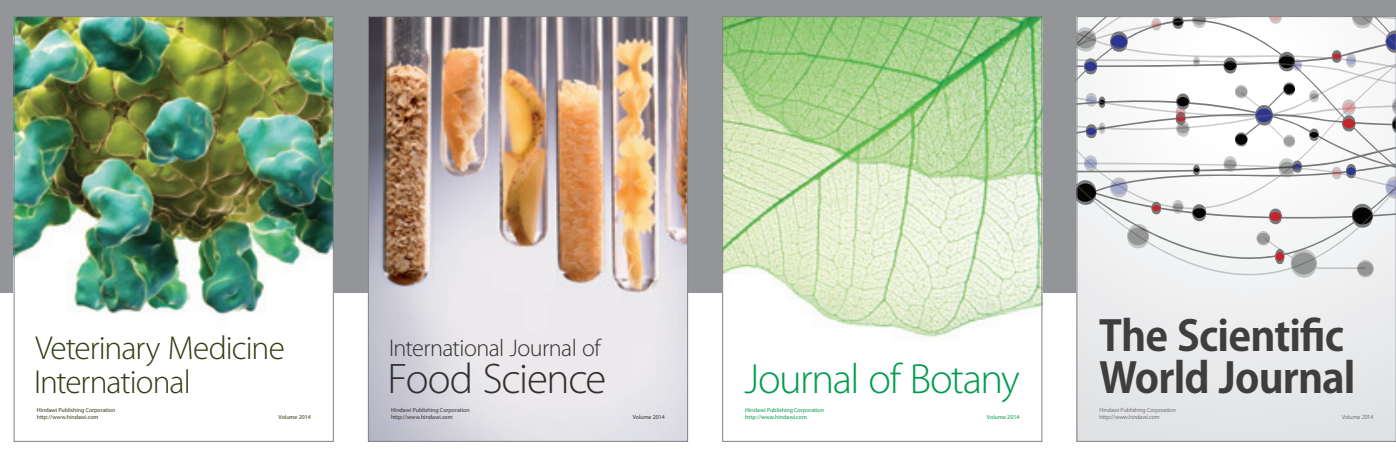

The Scientific World Journal
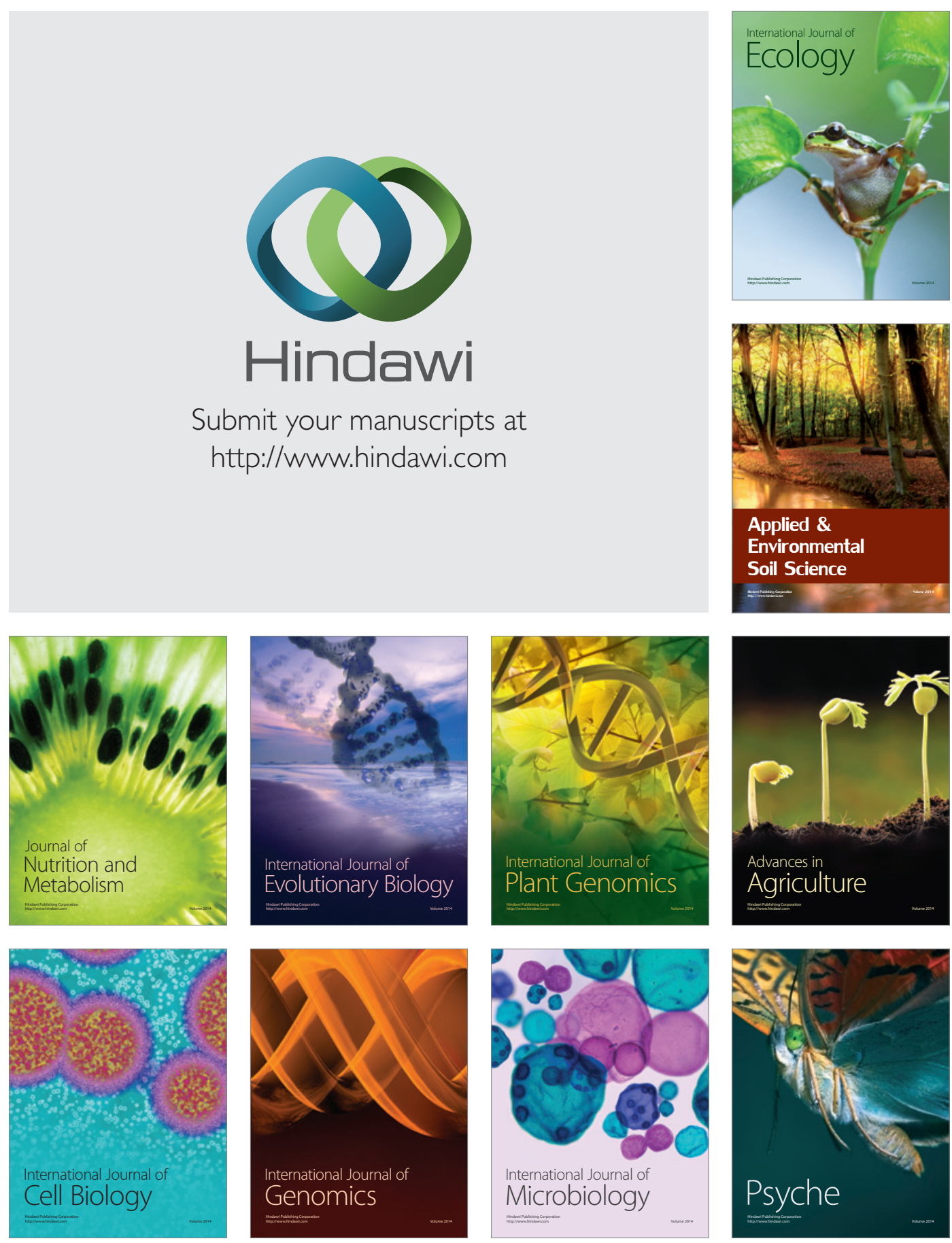